\title{
Enhanced peroxisomal $\beta$-oxidation metabolism in visceral adipose tissues of high-fat diet-fed obesity-resistant C57BL/6 mice
}

\author{
WEI-DONG XIE ${ }^{1}$, HUA WANG ${ }^{2}$, JIN-FANG ZHANG ${ }^{1,2}$, JIAN-NA LI ${ }^{1}$, \\ YI CAN ${ }^{1}, \mathrm{LV}_{\mathrm{QING}}{ }^{1}$, HSIANG-FU KUNG ${ }^{2}$ and YA-OU ZHANG ${ }^{1}$ \\ ${ }^{1}$ Life Science Division, Graduate School at Shenzhen, Tsinghua University, Shenzhen 518055; \\ ${ }^{2}$ Stanley Ho Centre for Emerging Infections, The Chinese University of Hong Kong, Hong Kong, SAR, P.R. China
}

Received November 4, 2010; Accepted December 31, 2010

DOI: $10.3892 /$ etm.2011.208

\begin{abstract}
This study aimed to investigate the potential mechanisms of natural resistance to high-fat diet-induced obesity. Four-week-old C57BL/6 mice were fed a high-fat diet for 6 weeks and were then designated as high-fat diet-fed obesity-prone (HOP) and obesity-resistant (HOR) animals. Their blood biochemistry was evaluated, and visceral adipose tissue samples were subjected to proteomic, Western blot and quantitative real-time PCR (q-PCR) analyses. The HOR mice showed reduced visceral fat weight and size, as well as lowered serum lipid and leptin levels. Proteomic analysis showed that enoyl coenzyme A hydratase 1, peroxisomal (Ech1) expression was significantly increased in their visceral adipose tissues. Moreover, other proteins, such as $\alpha$-tropomyosin, myosin light chain, urine-nucleoside phosphorylase and transgelin, were also significantly increased. Furthermore, q-PCR analysis showed that the expression of acyl-CoA oxidase 1 palmitoyl, enoyl-CoA hydratase/3-hydroxyacyl-CoA dehydrogenase and 3-oxoacyl-CoA thiolase responsible for peroxisomal $\beta$-oxidation was also up-regulated in the visceral adipose tissues of the HOR mice. The expression of peroxisome proliferator-activated receptor $\alpha(\operatorname{PPAR} \alpha)$ was increased in the HOR mice as shown by Western blot analysis. Obesityresistant animals show enhanced peroxisomal $\beta$-oxidation metabolism and reduced fat accumulation in visceral adipose tissues by up-regulating the expression of Ech1, peroxisomal or other related peroxisomal $\beta$-oxidation marker genes, which may be driven or enhanced by the up-regulation of the expression of PPAR $\alpha$. However, further validation in future studies is required.
\end{abstract}

Correspondence to: Dr Ya-Ou Zhang, Life Science Division, Graduate School at Shenzhen, Tsinghua University, Shenzhen 518055, P.R. China

E-mail: zhangyo@sz.tsinghua.edu.cn

Key words: diet-induced obesity, high-fat diet, enoyl coenzyme A hydratase 1 , peroxisomal, peroxisome proliferator-activated receptor $\alpha$

\section{Introduction}

Obesity has received considerable attention as a major health hazard due to the increase in the prevalence of obesity, not only in industrialized countries, but also in developing areas (1). Obesity, particularly abdominal obesity, contributes to many metabolic disorders, including metabolic syndrome, type 2 diabetes and cardiovascular diseases (2). However, the interventions of obesity remain a challenge, since the underlying mechanisms of its pathogenesis are being disclosed through a slow process.

Genetic and environmental factors may contribute to the development of obesity (3). A high-fat diet is one of the key factors causing body weight gain and the development of obesity (4). Current methods to treat obesity primarily involve supervised diet, exercise, behavior modification and use of anti-obesity drugs (5). However, some people remain lean despite consumption of a high-fat diet. The study of resistance to high-fat diet-induced obesity may be useful to understand the mechanisms involved in the development of obesity and to find new effective preventative measures.

Commonly, obesity-resistant animals either may eat less than obesity-prone rats or exhibit an increase total energy expenditure (6). Different levels of neuropeptide Y and leptin may also contribute to a propensity to obesity resistance $(7,8)$. Increased hepatocyte fatty acid oxidation in animals may be responsible for resistance to diet-induced obesity (9). However, the exact molecular mechanisms involved in obesity resistance require further investigation.

In the present study, we investigated the proteomic profiling of visceral adipose tissues in obesity-resistant mice exposed to a high-fat diet to further validate or determine the potential molecular mechanisms of obesity resistance using proteomic, Western blotting and real-time PCR methods.

\section{Materials and methods}

Animals and diets. Three-week-old male C57BL/6 mice [SPF grade, certified no. SCXK (Guangdong) 2003-0002] were obtained from Guangdong Medical Laboratory Animal Center (Guangzhou, Guangdong, China). Animals were kept in an environmentally controlled breeding room (temperature, $20 \pm 2^{\circ} \mathrm{C}$; humidity, $60 \pm 5 \%$; 12 -h dark/light cycle). They were 
Table I. Mitochondrial and peroxisomal $\beta$-oxidation genes.

\begin{tabular}{lclc}
\hline Gene names & NCBI accession no. & \multicolumn{1}{c}{ Primers (5' to 3') } & Sizes (bp) \\
\hline Acox1 & NM_015729 & $\begin{array}{l}\text { Forward: CCGCCTATGCCTTCCACT } \\
\text { Reverse: ACCGCAAGCCATCCGACA }\end{array}$ & 182 \\
Ehhadh & NM_023737.3 & $\begin{array}{l}\text { Forward: TGGACCATACGGTTAGAG } \\
\text { Reverse: CAATCCGATAGTGACAGC }\end{array}$ & 213 \\
Acaal & NM_130864.3 & $\begin{array}{l}\text { Forward: GATGACCTCGGAGAATGTGG } \\
\text { Reverse: CCTGAGACACGGTGATGGT }\end{array}$ & 188 \\
Hadhb & NM_145558 & $\begin{array}{l}\text { Forward: TGTCAGGCACTTCGTAT } \\
\text { Reverse: TAGCCACATTGCTTGTT }\end{array}$ & 153 \\
GAPDH & NM_008084 & Forward: TCTCCTGCGACTTCAACA & 178 \\
& & Reverse: TGGTCCAGGGTTCTTACT & 178 \\
\hline
\end{tabular}

fed standard laboratory chow with water ad libitum and were fasted from 9:00 am to 3:00 pm before the experiments. Our research was conducted in accordance with the Declaration of Helsinki and/or with the Guide for the Care and Use of Laboratory Animals as adopted and promulgated by the United States National Institutes of Health and approved by the Animal Welfare and Ethics Committee of Tsinghua University, China. High-fat diets were purchased from the Institute of Laboratory Animal Science, Chinese Academy of Medical Science. High-fat diets contained $35 \%$ crude protein, $20 \%$ crude fat and $25 \%$ crude carbohydrates $(\mathrm{g} / \mathrm{g})$. Total calorie intake from the high-fat diets was $18 \mathrm{KJ}$ per gram ( $40 \%$ calories in fat).

Experimental procedure. Mice aged 4 weeks were separately placed in metabolic cages (Tecniplast ${ }^{\circledast}$, Italy) and had free access to water and high-fat diets. Body weight was monitored once a week. Dietary and water intake, urine volume and fecal weight for each mouse were recorded while in the metabolic cage for $24 \mathrm{~h}$, once a week. Total calorie intake was calculated according to the dietary calorie intake and expressed as $\mathrm{KJ} / \mathrm{g} /$ day. Collected feces were used for lipid assaying. After 6 weeks of high-fat diet feeding, the mice were ranked in the upper and lower quarters for weight gain and designated as obesity-prone and obesity-resistant $(\mathrm{n}=10)$, respectively. On the 6th week, the animals were weighed and anesthetized by an intraperitoneal injection of pentobarbital at a dose of $35 \mathrm{mg} /$ $\mathrm{kg}$. Blood was collected from the tail vein prior to the 6-week treatment and then from the orbital plexus after the 6-week treatment. Serum was isolated by centrifugation at $1,500 \mathrm{x} g$ at $4^{\circ} \mathrm{C}$ for $10 \mathrm{~min}$ and stored at $-80^{\circ} \mathrm{C}$ until it was used for blood glucose and lipid assays. Following blood collection, the anesthetized mice were sacrificed by cervical dislocation. Visceral adipose tissues (perigonadal fat, the main part of the internal white adipose tissues) were removed from the animals and immediately weighed. These samples were instantly frozen in liquid nitrogen and then stored at $-80^{\circ} \mathrm{C}$ until they were used for biochemical analysis.

Calculation of the size of single adipocytes. Part of the freshly removed adipose tissue samples were fixed in $1 \%$ glutaraldehyde in $0.1 \mathrm{M}$ phosphate-buffered saline ( $\mathrm{pH} 7.4$ ) for $72 \mathrm{~h}$ and then processed for routine paraffin-wax histology. Sections were stained with hematoxylin and eosin. Non-overlapping adjacent sections were observed for adipocytes to measure fat cell size from each group sample. The adipocytes $(n=100)$ in the sections were recorded with x200 magnification by using a fully automated inverted research microscope (Leica DMI6000 B, Germany). The size of each adipocyte is expressed as the area of a single adipocyte in the sections and calculated according to the formula: Area $=[\pi \mathrm{x}$ long diameter $(\mu \mathrm{m}) \mathrm{x}$ short diameter $(\mu \mathrm{m})] / 4$.

Biochemical analysis. Blood glucose and triglycerides, total cholesterol, low-density lipoprotein cholesterol and highdensity lipoprotein cholesterol $(n=10)$ were estimated using commercial kits (BioSino Bio-Technology and Science Inc., Beijing, China) (10-14). Blood leptin levels were assayed through the avidin-biotin complex-ELISA kit (Shanghai Westang Bio-Tech, China). Fecal lipid assays were conducted according to the previous protocol (15).

2-Dimensional electrophoresis. Freshly prepared protein samples from visceral adipose tissues of three randomly selected animals in each group were analyzed by 2-dimensional electrophoresis (2DE). Protein extraction of adipose tissues, isoelectric focusing electrophoresis, second dimensional separation of samples, gel staining, image analysis, tryptic in-gel digestion, MALDI-TOF/TOF mass spectrometric analysis and database search for protein identification were carried out according to previously described methods (15).

Western blotting. Freshly prepared visceral adipose tissues $(n=5)$ were homogenized and lysed with NETN buffer $(20 \mathrm{mM}$ Tris- $\mathrm{HCl}, \mathrm{pH} 7.8,1 \mathrm{mM}$ EDTA, $50 \mathrm{mM}$ sodium chloride and $0.5 \%$ NP-40), and lysates were centrifuged at $12,000 \mathrm{rpm}$ at $4^{\circ} \mathrm{C}$ for 2-10 min. Supernatants were collected, and the protein concentration was determined by a bicinchoninic acid protein assay kit (Nanjing Jiancheng Biotech, China). Western blot analysis was carried out according to the manufacturer's protocol. Antibodies against peroxisome proliferator-activated receptor $\alpha$ and $\gamma$ (PPAR $\alpha$ and PPAR $\gamma$; Wuhan Boster Bio-Tech, China), enoyl coenzyme A hydratase 1, peroxisomal (Ech1; Beijing Aviva Systems Biology, China) and $\beta$-actin (Santa 
A

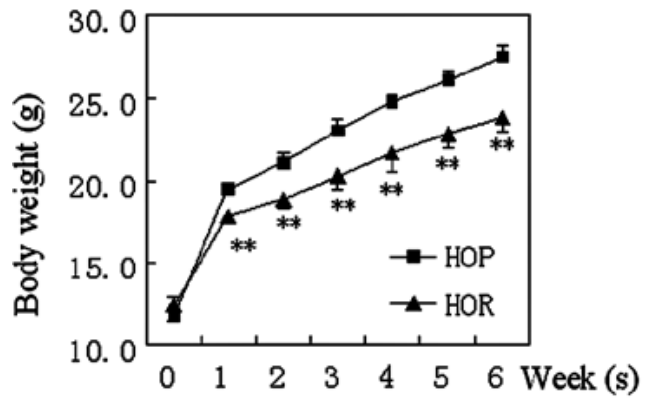

C

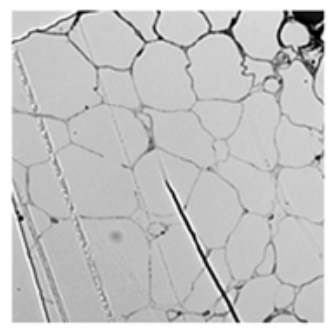

HOP

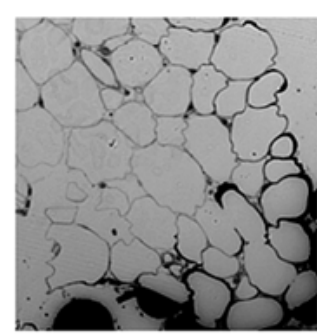

HOR
B

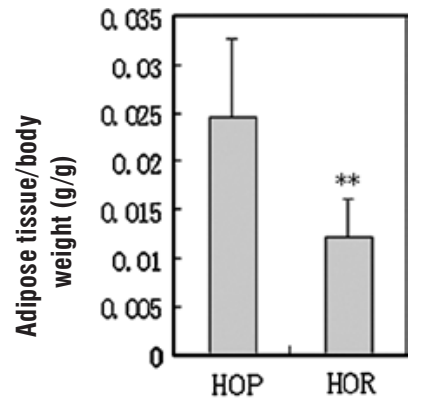

D

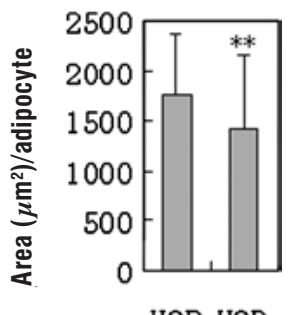

HOP HOR

Figure 1. Changes in the body weight $(A ; n=10)$, visceral fat weight $(B ; n=10)$, and visceral adipocyte size $(C$ and $D ; n=100)$ in obesity-prone and obesityresistant mice fed a high-fat diet for 6 weeks. HOP, high-fat diet-fed obesity-prone mice; HOR, high-fat diet-fed obesity-resistant mice. Data are expressed as the mean $\pm \mathrm{SD} .{ }^{* *} \mathrm{P}<0.01$ vs. HOP.

Cruz Biotechnology, Inc.) were used. Protein expression was visualized with horseradish peroxidase-conjugated secondary antibodies (Amersham Biosciences, USA; 1:2,000) and enhanced chemiluminescence (KPL, USA).

Quantitative real-time PCR. Approximately $100 \mathrm{mg}$ of visceral adipose tissues were removed and immediately frozen in liquid nitrogen $(n=5)$. Total RNA was extracted using TRIzol reagent (Invitrogen) according to the manufacturer's instructions. Reverse transcription was carried out using a PrimeScript $^{\mathrm{TM}}$ 1st Strand cDNA Synthesis kit (Takara, Dalian, P.R. China), and the cDNA fragments were amplified using Taq DNA polymerase (Takara) according to the manufacturer's instructions. There are various genes mainly responsible for mitochondrial and peroxisomal $\beta$-oxidation (16). These include the three peroxisomal $\beta$-oxidation genes, acyl-CoA oxidase 1 palmitoyl (Acox1), enoyl-CoA hydratase/3-hydroxyacyl-CoA dehydrogenase (Ehhadh), 3-oxoacyl-CoA thiolase (Acaa1); and one mitochondrial $\beta$-oxidation gene, hydroxyacyl-CoA dehydrogenase/3-ketoacyl-CoA thiolase/enoyl-CoA hydratase (Hadhb, trifunctional protein, $\beta$ subunit). In the present study, these genes were chosen for quantitative PCR analysis, and the primers were synthesized by Invitrogen (Table I). Glyceraldehyde-3-phosphate dehydrogenase (GAPDH) was used as an internal control for normalization. Quantitative real-time PCR (q-PCR) analysis was conducted using the method of SYBR ${ }^{\circledR}$ Green I dye according to the protocol of the kit (code no. DRR081S; Takara) in the ABI PRISM 7300 real-time PCR System (Applied Biosystems, USA). The q-PCR analysis was performed in two steps: i) cDNA samples were pre-denatured at $95^{\circ} \mathrm{C}$ for $30 \mathrm{sec}$ in the first stage; and ii) denatured cDNA samples were amplified by 40 cycles at $95^{\circ} \mathrm{C}$ for $5 \mathrm{sec}$ and at $60^{\circ} \mathrm{C}$ for $31 \mathrm{sec}$ in the second stage. Data were expressed as raw relative quantitation $\left(2^{-\Delta \Delta C t}\right)$.
Statistical analysis. Data were expressed as the mean \pm SD. Statistical analysis was performed using ANOVA. The Newman-Keuls comparisons were used to determine the source of significant differences where appropriate. P-values $<0.05$ were considered statistically significant.

\section{Results}

Body weight, visceral fat index, energy intake, fecal lipid excretion and body temperature. The HOR mice significantly exhibited decreased body weight $(\mathrm{P}<0.01$ vs. HOP $)$ and visceral adipose tissue weight $(\mathrm{P}<0.01$ vs. HOP) compared to the HOP control after 6 weeks of exposure to the high-fat diet (Fig. 1). The size of visceral adipocytes (areas/single cells in sections) in the HOR mice was $20 \%$ less than that in the HOP control $(\mathrm{P}<0.01$ vs. HOP, $\mathrm{n}=100)$. No significant difference in dietary caloric intake, water intake and urine excretions was observed between the two groups after normalization for body weight (data not shown). Total calorie count from fecal fat of each group was crudely calculated according to fecal weights and fecal triglycerides and was $<1 \%$ of the total dietary caloric intake, although a moderate decrease in fecal lipid excretions was noted in the HOR mice. Therefore, caloric differences in intestinal lipid absorption were negligible between the groups.

Serum biochemical parameters. Fasting blood glucose levels did not demonstrate a significant change between the HOP and HOR mice at any week $(\mathrm{P}>0.05)$ (Table II). A moderate decrease in the levels of serum triglyceride $(\mathrm{P}<0.01 \mathrm{vs}$. HOP), total cholesterol $(\mathrm{P}<0.05$ vs. HOP) (on the 6th week) and low-density lipoprotein cholesterol (on the 6th week) $(\mathrm{P}<0.05$ vs. HOP) was observed in the HOR mice compared to the HOP control. In addition, there was a $>50 \%$ decrease in the serum leptin concentration in the HOR mice compared to the 
Table II. Changes in the blood glucose and lipid parameters in mice after 6 weeks of treatment.

\begin{tabular}{lrr}
\hline & HOP & HOR \\
\hline Week 0 & & $6.05 \pm 0.81$ \\
Fasting blood glucose (mmol/l) & $1.13 \pm 0.45$ & $1.09+0.23$ \\
Serum triglycerides (mmol/l) & $85.70 \pm 15.40$ & $89.10 \pm 9.70$ \\
Serum total cholesterol (mg/dl) & & $8.52 \pm 0.95$ \\
Week 6 & $8.79 \pm 1.31$ & $0.84 \pm 0.17^{\mathrm{b}}$ \\
Fasting blood glucose (mmol/l) & $1.08 \pm 0.15$ & $117.00 \pm 9.30^{\mathrm{a}}$ \\
Serum triglycerides (mmol/l) & $128.60 \pm 11.40$ & $51.80 \pm 7.80^{\mathrm{a}}$ \\
Serum total cholesterol (mg/dl) & $62.40 \pm 9.50$ & $45.50 \pm 3.00$ \\
Low-density lipoprotein cholesterol (mg/dl) & $45.10 \pm 2.90$ & $132.70 \pm 77.80^{\mathrm{a}}$ \\
High-density lipoprotein cholesterol $(\mathrm{mg} / \mathrm{dl})$ & $330.00 \pm 129.30$ & \\
Serum leptin (pg/ml) & & \\
\hline
\end{tabular}

HOP, high-fat diet-fed obesity-prone mice; HOR, high-fat diet-fed obesity-resistant mice. Data are expressed as the mean \pm SD $(\mathrm{n}=10)$. aP $<0.05,{ }^{\text {b }}<0.01$ vs. HOP.

Table III. Differentially expressed proteins in adipose tissues between the HOR and HOP mice.

\begin{tabular}{|c|c|c|c|c|c|c|}
\hline $\begin{array}{l}\text { Spot } \\
\text { no. }\end{array}$ & $\begin{array}{l}\text { Protein } \\
\text { name }\end{array}$ & $\mathrm{Mr} / \mathrm{PI}$ & $\begin{array}{l}\text { NCBI } \\
\text { accession no. }\end{array}$ & $\begin{array}{l}\text { Protein } \\
\text { score }\end{array}$ & $\begin{array}{c}\text { Sequence } \\
\text { coverage }(\%)\end{array}$ & $\begin{array}{l}\text { Fold } \\
\text { change }\end{array}$ \\
\hline 2 & $\alpha$-tropomyosin & $32.7 / 4.7$ & GI 157787199 & 108 & 16 & $\mathrm{HOR} \uparrow 6.4$ \\
\hline 3 & $\begin{array}{l}\text { Myosin light chain, phosphorylatable, } \\
\text { fast skeletal muscle }\end{array}$ & $18.9 / 4.8$ & GI 7949078 & 175 & 52 & $\mathrm{HOR} \uparrow 4.5$ \\
\hline 4 & $\begin{array}{l}\text { Purine-nucleoside } \\
\text { phosphorylase }\end{array}$ & $32.2 / 5.8$ & GI 7305395 & 104 & 35 & $\mathrm{HOR} \uparrow 6.0$ \\
\hline 5 & $\begin{array}{l}\text { Enoyl coenzyme A hydratase } 1, \\
\text { peroxisomal }\end{array}$ & $36.1 / 7.6$ & GI 7949037 & 217 & 24 & $\mathrm{HOR} \uparrow 3.5$ \\
\hline 6 & Transgelin & $22.6 / 8.85$ & GI 6755714 & 129 & 65 & $\mathrm{HOR} \uparrow 3.1$ \\
\hline 8 & Vimentin & $51.5 / 5.00$ & GI 2078001 & 224 & 28 & HOR (-) \\
\hline
\end{tabular}

$\uparrow$, up-regulation; -, none. HOP, high-fat diet-fed obesity-prone mice; HOR, high-fat diet-fed obesity-resistant mice.

HOP control $(\mathrm{P}<0.05$ vs. HOP); this indicates that HOR mice have less leptin resistance.

Differentially expressed proteins in adipose tissues detected using 2-dimensional electrophoresis. Adipose tissues serve as the main marker of obesity. Here, 2DE was used to investigate the differences in the expression of proteins in adipose tissues between obesity-prone and obesity-resistant mice. Proteins were regarded as differentially expressed when the magnitude of the difference was >2-fold; this result was reproduced twice. As a result, six proteins were found differentially expressed between the HOP and HOR mouse samples (Table III). HOR mice displayed a significant change in the expression of proteins responsible for cell skeleton, nutritional metabolism, cell proliferation and divisions. Full images of the 2DE are shown in Fig. 2. Protein spots of interest (those directly contributing to energy metabolism) are marked and enlarged in Fig. 3. Ech1 expression, a key enzyme associated with peroxisomal fat oxidation, was significantly increased by 3.5 -fold in the visceral adipose tissues of the HOR mice compared to the HOP control.

Ech1, PPAR $\alpha$ and PPAR expression in adipose tissues detected using Western blotting. Western blot analysis further confirmed the expression of Ech1 based on the results from proteomic trials. Ech1 $(\mathrm{P}<0.01)$ was significantly increased in the adipose tissues of HOR mice compared to the HOP control as shown in Fig. 3. In addition, PPAR $\alpha$ plays an important role in fat metabolism by affecting the expression of related enzymes. In this study, PPAR $\alpha$ was significantly increased in the visceral adipose tissues in both the HOR mice and the HOP control $(\mathrm{P}<0.01)$. Moreover, PPAR $\gamma$ is a key factor responsible for adipocyte differentiation. Here, the expression of PPAR $\gamma$ was significantly down-regulated in the adipose tissues of the HOR mice compared to that of the HOP control $(\mathrm{P}<0.01)$. 

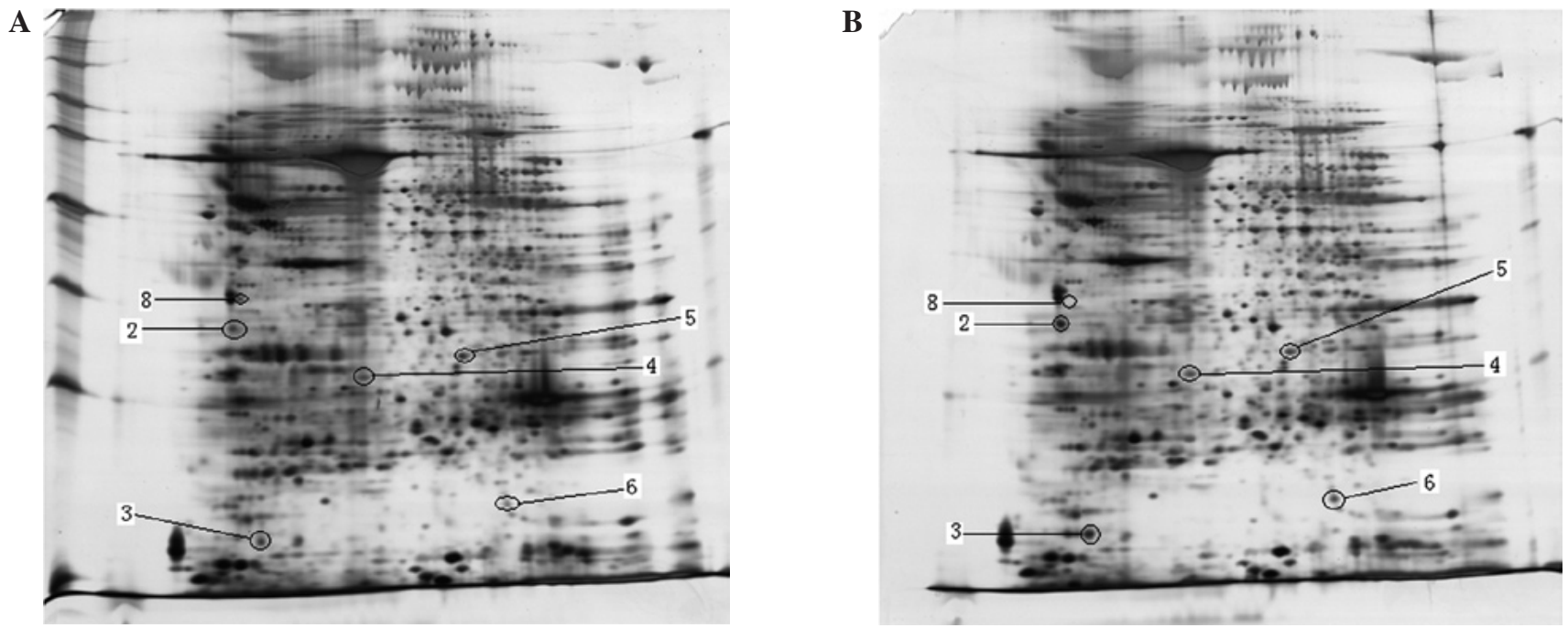

Figure 2. Image of $2 \mathrm{DE}$ of the visceral adipose tissues in HOP (A) and HOR (B) $(n=3)$ mice. Differentially expressed proteins are indicated with a circle. Protein spots: 2, $\alpha$-tropomyosin; 3, myosin light chain, phosphorylatable, fast skeletal muscle; 4, purine-nucleoside phosphorylase; 5 , enoyl coenzyme A hydratase 1, peroxisomal; 6, transgelin; 8, vimentin. HOP, high-fat diet-fed obesity-prone mice; HOR, high-fat diet-fed obesity-resistant mice.

A

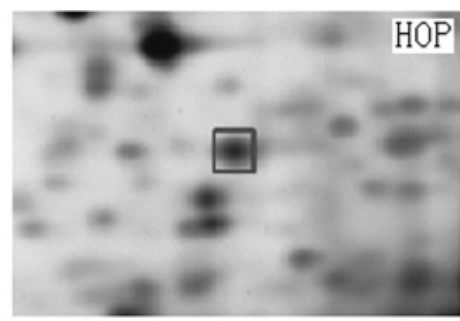

C

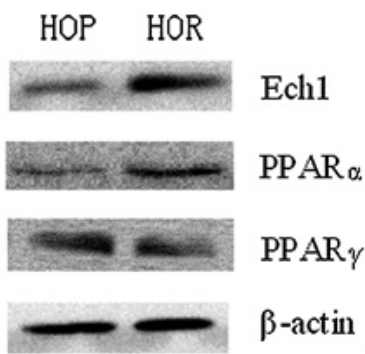

B

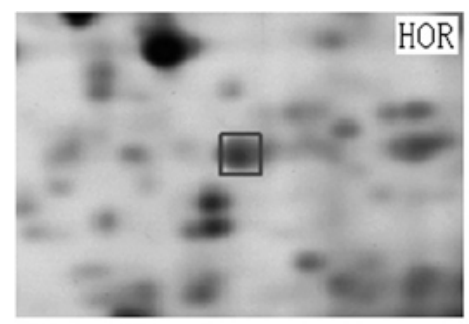

D

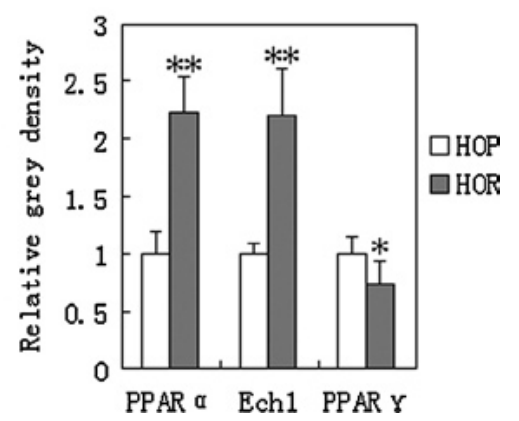

Figure 3. Images of the differential expression of enoyl coenzyme A hydratase 1, peroxisomal (Ech1) determined by $2 \mathrm{DE}$ in the visceral adipose tissues of HOP (A) and HOR (B) mice after 6 weeks of treatment. Spots of interest are marked and enlarged ( $n=3$ ). Protein expression (C) and relative grey densities (D) as determined by Western blotting in visceral adipose tissues of HOP and HOR mice. Data are expressed as the mean \pm SD $(n=5)$. ${ }^{*} P<0.05$, ${ }^{* *} \mathrm{P}<0.01$ vs HOP. HOP, high-fat diet-fed obesity-prone mice; HOR, high-fat diet-fed obesity-resistant mice.

Expression of mitochondrial and peroxisomal $\beta$-oxidation genes determined by $q$-PCR. Using q-PCR analysis we further investigated the expression of other mitochondrial and peroxisomal key $\beta$-oxidation genes to provide additional useful information. The q-PCR results showed that the expression of Acox1, Ehhadh and Acaal mRNAs was significantly increased by $43.9(\mathrm{P}<0.01), 39.3(\mathrm{P}<0.01)$ and $111.4 \%(\mathrm{P}<0.01)$ in the visceral adipose tissues of the HOR mice compared to the expression levels in the HOP control (Fig. 4). However, the expression of Hadhb was not significantly altered in the visceral adipose tissues of the HOR mice compared to that of the HOP controls.

\section{Discussion}

In a previous study, outbred animals that showed heterogeneous responses to high-fat diets were used to study obesity-prone and obesity-resistant animals (17). In the present study, inbred animals (C57BL/6 mice) also displayed different responses to high-fat diets as previously described (18). Actually, C57BL/6 mice show obesity-prone and obesity-resistant phenotypes even when exposed to a low-fat diet (15). Obesity-resistant mice exhibited reduced body weight and visceral fat accumulation. This may account for a significant decrease in the serum leptin level, since leptin is produced principally by white fat 


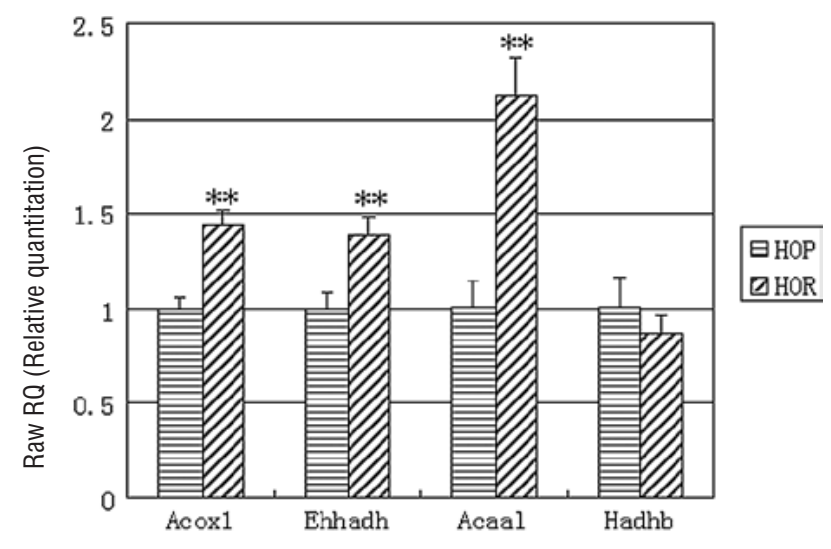

Figure 4. Expression of Acox1, Ehhadh, Acaal and Hadhb mRNAs in the visceral adipose tissues in mice determined by quantitative real-time PCR. HOP, high-fat diet-fed obesity-prone mice; HOR, high-fat diet-fed obesityresistant mice. Data are expressed as the mean $\pm \mathrm{SD}(\mathrm{n}=5) .{ }^{* *} \mathrm{P}<0.01$ vs. HOP.

(19). Obese individuals, however, often have increased leptin concentrations and are associated with leptin resistance (20). However, obesity-resistant mice appear to have less leptin resistance and serum lipid levels when exposed to high-fat diets. Both leptin resistance and hyperlipidemia are associated with cardiovascular diseases $(21,22)$. Therefore, obesity resistance may be useful to prevent cardiovascular risks derived from obesity. Despite this, the mechanisms underlying obesity resistance remain undetermined.

Caloric intake is an important factor affecting body weight gain (23). After normalization of body weight, no significant difference in caloric intake was observed between obesityprone and obesity-resistant animals; this suggests that caloric intake may not have been a key factor affecting visceral fat accumulation in this study. Intestinal lipid absorption is an important factor affecting body weight (24). Here, the difference in intestinal lipid absorption rate between obesity-prone and obesity-resistant mice was minimal and did not contribute to visceral fat accumulation. It is unclear whether high-fat diet-induced obesity-resistant animals have an altered energy metabolism potential in visceral adipose tissues, since these tissues are important markers for obesity.

The proteomic method provides much information regarding a disease when the mechanisms involved in a certain disease are not known $(25,26)$, although it may be considered as a 'fishing trip'. The previous study found various differentiated expressed proteins involved in energy metabolism, glycolysis and fat synthesis in visceral adipose tissues of low-fat diet-fed obesity-prone and obesity-resistant mice (15). Here, the HOR mice displayed a significant change in expression of proteins responsible for cell skeleton, nutritional metabolism, cell proliferation and division. Peroxisomal Ech1 functions in the auxiliary step of the fatty acid $\beta$-oxidation pathway (27) and plays an important role in fat metabolism. In this study, Ech1 expression was significantly increased in the adipose tissues of the HOR mice, which may be associated with an accelerated fat metabolism resulting in reduced visceral fat accumulation and serum lipid levels. Apart from Ech1, other differentially expressed proteins, such as $\alpha$-tropomyosin, myosin light chain, urinenucleoside phosphorylase and transgelin, were noted in the HOR mice. Although their functions remain unknown, they may be utilized in the development of biomarkers of obesity resistance.

Following proteomic analysis, increased expression of Ech1 was further confirmed by Western blot analysis. PPAR $\alpha$, an essential transcription factor, is involved in the up-regulation of lipid metabolism by affecting fatty acid-metabolizing enzymes (28). In a previous study, fenofibrate, a PPAR $\alpha$ agonist, reduced the visceral fat accumulation in mice exposed to high-fat diets (29). PPAR $\alpha$ is highly expressed in the liver and muscles, but is modestly expressed in white adipose tissues (30). In this study, increased PPAR $\alpha$ expression in the visceral adipose tissues of HOR mice as determined using Western blotting may have contributed to enhance fat metabolism. This increase may have up-regulated the expression of Ech1. Fenofibrate, an agonist of PPAR $\alpha$, was found to up-regulate the expression of Ech1 (31). PPAR $\gamma$, an essential transcription factor, is a critical determinant of body fat distribution in humans and mice (32). However, in this study, PPAR $\gamma$ expression was decreased in the visceral adipose tissues of the HOR mice, suggesting that this decrease may inhibit adipogenesis. The reasons for the 'teeter-tottering' expression of PPAR $\alpha$ and $\operatorname{PPAR} \gamma$ require further elucidation.

In addition, the expression of several key genes responsible for fat $\beta$-oxidation were determined using q-PCR analysis. Acox1, Ehhadh and Acaal are three peroxisomal $\beta$-oxidation marker enzymes, while Hadhb is a key mitochondrial $\beta$-oxidation enzyme (16). Acox1 catalyzes the first step of peroxisomal $\beta$-oxidation and the dehydrogenation of acyl-CoA esters to trans-2-enoyl-CoAs. Ehhadh catalyzes the second and third steps of peroxisomal $\beta$-oxidation, hydration and dehydrogenation of enoyl-CoA esters to ketoacyl-CoA. Acaal cleaves 3-oxoacyl-CoA to acetyl-CoA. Hadhb, which contains hydroxyacyl-CoA dehydrogenase, 3-ketoacyl-CoA thiolase and enoyl-CoA hydratase, is a trifunctional protein $\beta$ subunit. In this study, increased expression of the three peroxisomal $\beta$-oxidation marker genes, but not that of the mitochondrial $\beta$-oxidation key gene, suggests that HOR mice may exhibit enhanced expression of peroxisomal $\beta$-oxidation marker enzymes thus promoting peroxisomal $\beta$-oxidation metabolism instead of mitochondrial $\beta$-oxidation in visceral adipose tissues. These up-regulated marker genes further suggest that visceral adipose tissues may have increased peroxisomal $\beta$-oxidation metabolism.

This study suggests that obesity-resistant animals may show enhanced peroxisomal $\beta$-oxidation metabolism and thus reduced fat accumulation in visceral adipose tissues by up-regulation of the expression of Ech1, peroxisomal, or other peroxisomal $\beta$-oxidation marker genes, such as Acox1, Ehhadh and Acaal. This up-regulation may be driven or enhanced by up-regulated expression of PPAR $\alpha$. Moreover, other proteins, such as $\alpha$-tropomyosin, myosin light chain, urine-nucleoside phosphorylase and transgelin, may be utilized in the development of biomarkers for obesity resistance. Further studies should focus on: i) how peroxisomal $\beta$-oxidation metabolism functions in the visceral adipose tissues of obesity-resistant animals; and ii) which biomarkers are involved in obesityresistance to a high-fat diet. 


\section{Acknowledgements}

This study was supported by the National Natural Science Foundation of China (nos. 30871428 and 81072680), the Natural Science Foundation of Guangdong Province (10151805702000002), the Specialized Research Fund for the Doctoral Program of Higher Education of China (20100002120017), the China Postdoctoral Science Foundation (20060390460), and the Tertiary College Science Foundation of Nanshan, Shenzhen (2008028).

\section{References}

1. Nguyen DM and El-Serag HB: The epidemiology of obesity Gastroenterol Clin North Am 39: 1-7, 2010.

2. Jia WP, Wang C, Jiang S and Pan JM: Characteristics of obesity and its related disorders in China. Biomed Environ Sci 23: 4-11, 2010.

3. Schrauwen P and Westerterp KR: The role of high-fat diets and physical activity in the regulation of body weight. Br J Nutr 84 417-427, 2000

4. Pagliassotti MJ, Gayles EC and Hill JO: Fat and energy balance. Ann NY Acad Sci 827: 431-448, 1997.

5. Nair RP and Ren J: Pharmacotherapy of obesity - benefit, bias and hyperbole. Curr Med Chem 16: 1888-1897, 2009.

6. Jackman MR, MacLean PS and Bessesen DH: Energy expenditure in obesity-prone and obesity-resistant rats before and after the introduction of a high-fat diet. Am J Physiol Regul Integr Comp Physiol 299: R1097-R1105, 2010.

7. Takahashi N, Patel HR, Qi Y, et al: Divergent effects of leptin in mice susceptible or resistant to obesity. Horm Metab Res 34 691-697, 2002.

8. Primeaux SD, Barnes MJ and Bray GA: Olfactory bulbectomy increases food intake and hypothalamic neuropeptide $\mathrm{Y}$ in obesity-prone but not obesity-resistant rats. Behav Brain Res 180: 190-196, 2007.

9. Ji H and Friedman MI: Reduced hepatocyte fatty acid oxidation in outbred rats prescreened for susceptibility to diet-induced obesity. Int J Obesity 32: 1331-1334, 2008.

10. Trinder P: Determination of glucose in blood using glucose oxidase with an alternative oxygen acceptor. Ann Clin Biochem 6: 24-27, 1969.

11. Allain CC, Poon LC, Chan CS, et al: Enzymatic determination of total cholesterol. Clin Chem 20: 470-475, 1974.

12. Fossati P and Prencipe L: Serum triglycerides determined colorimetrically with an enzyme that produce hydrogen peroxide. Clin Chem 28: 2077-2080, 1982.

13. Izzo C, Grillo F and Murador E: Improved method for determination of high-density-lipoprotein cholesterol I. Isolation of high-density lipoproteins by use of polyethylene glycol 6000 . Clin Chem 27: 371-374, 1981

14. Kerscher L, Schiefer S, Draeger B, et al: Precipitation methods for the determination of LDL-cholesterol. Clin Biochem 18 $118-125,1985$.
15. Xie WD, Wang $\mathrm{H}$, Zhang JF, et al: Proteomic profile of visceral adipose tissues between low-fat diet-fed obesity-resistant and obesity-prone C57BL/6 mice. Mol Med Rep 3: 1047-1052, 2010.

16. Guo Y, Jolly RA, Halstead BW, et al: Underlying mechanisms of pharmacology and toxicity of a novel PPAR agonist revealed using rodent and canine hepatocytes. Toxicol Sci 96: 294-309, 2007.

17. Pagliassotti MJ, Knobel SM, Shahrokhi KA, et al: Time course of adaptation to a high-fat diet in obesity-resistant and obesityprone rats. Am J Physiol 267: R659-R664, 1994.

18. Xie WD, Zhang YO, Wang NL, et al: Novel effects of macrostemonoside A, a compound from Allium macrostemon Bung, on hyperglycemia, hyperlipidemia, and visceral obesity in high-fat diet-fed C57BL/6 mice. Eur J Pharmacol 599: 159-165, 2008.

19. Trayhurn P and Beattie JH: Physiological role of adipose tissue: white adipose tissue as an endocrine and secretory organ. Proc Nutr Soc 60: 329-339, 2001.

20. Rosicka M, Krsek M, Matoulek M, et al: Serum ghrelin levels in obese patients: the relationship to serum leptin levels and soluble leptin receptor levels. Physiol Res 52: 61-66, 2003.

21. Luo JD, Zhang GS and Chen MS: Leptin and cardiovascular diseases. Timely Top Med Cardiovasc Dis 9: E34, 2005.

22. Kannel WB and Vasan RS: Triglycerides as vascular risk factors: new epidemiologic insights. Curr Opin Cardiol 24: 345-350, 2009.

23. Swinburn B, Sacks G and Ravussin E: Increased food energy supply is more than sufficient to explain the US epidemic of obesity. Am J Clin Nutr 90: 1453-1456, 2009.

24. Kaplan LM: Pharmacologic therapies for obesity. Gastroenterol Clin North Am 39: 69-79, 2010.

25. Huzarewich RL, Siemens CG and Booth SA: Application of "omics" to prion biomarker discovery. J Biomed Biotechnol 2010: 613504, 2010.

26. Halvorsen YD, Wilkison WO and Briggs MR: Human adipocyte proteomics - a complementary way of looking at fat. Pharmacogenomics 1: 179-185, 2000.

27. FitzPatrick DR, Germain-Lee E and Valle D: Isolation and characterization of rat and human cDNAs encoding a novel putative peroxisomal enoyl-CoA hydratase. Genomics 27: 457-466, 1995.

28. Aoyama T, Peters JM, Iritani N, et al: Altered constitutive expression of fatty acid-metabolizing enzymes in mice lacking the peroxisome proliferator-activated receptor alpha (PPARalpha). J Biol Chem 273: 5678-5684, 1998.

29. Xie WD, Nie Y, Du LJ, et al: Preventive effects of fenofibrate on insulin resistance, hyperglycaemia, visceral fat accumulation in NIH mice induced by small-dose streptozotocin and lard. Pharmacol Res 55: 392-399, 2007.

30. Abbott BD: Review of the expression of peroxisome proliferatoractivated receptors alpha (PPAR alpha), beta (PPAR beta), and gamma (PPAR gamma) in rodent and human development. Reprod Toxicol 27: 246-257, 2009.

31. Miyazaki M, Nakagawa I, Koga S, et al: Proteomics analysis of cardiac muscle from rats with peroxisomal proliferator-activated receptor alpha (PPARalpha) stimulation. J Toxicol Sci 35: 131-135, 2010.

32. Tsai YS and Maeda N: PPARgamma: a critical determinant of body fat distribution in humans and mice. Trends Cardiovasc Med 15: 81-85, 2005. 